\title{
The Application of Knowledge Map in Construction Knowledge Management
}

\author{
Meng-Hsueh LEE ${ }^{\mathrm{a}}$, Yu-Cheng LIN ${ }^{\mathrm{b}}$ and H. Ping TSERNG ${ }^{\mathrm{c}}$ \\ a Ph.D. Student, Department of Civil Engineering, National Taiwan Univ., Taipei, Taiwan. \\ D92521016@ntu.edu.tw \\ b Ph.D. Candidate, Department of Civil Engineering, National Taiwan Univ., Taipei, Taiwan. \\ yucheng@ce.ntu.edu.tw \\ c Associate Professor, Department of Civil Engineering, National Taiwan Univ., Taipei, Taiwan. \\ hptserng@ce.ntu.edu.tw
}

\begin{abstract}
Knowledge map is one of the most important and useful tools in the knowledge management field. Knowledge map can be used to effectively plan the implementation of a knowledge management strategy for a term, department, and enterprise. With the assistance of knowledge map, users cannot only easily understand and identify where the knowledge in located in the system, but can also determine what intellectual assets are essential to their enterprise. The methodology uses a knowledge map as a tool to represent knowledge in implementing construction knowledge management effectively. The main contents of this paper includes (1) study current knowledge management and map application system's function and characteristics; (2)propose the process for creating a construction knowledge map; (3) propose important factors and analysis in knowledge map design. Furthermore, a construction classification structure is provided in the paper and a scenario is explained to describe the framework of building construction knowledge map by studying review literature and experts symposium.
\end{abstract}

Keywords: Knowledge Management; Knowledge Map; Construction Industry; Construction Project.

\section{Introduction}

Knowledge map is a very important field of study in the knowledge management field. One of the most important parts that construction industries focus on is how to extract tacit knowledge in the enterprise. Knowledge map is an important connection to improve knowledge exchange. The main contains of this paper include (1)study current knowledge management and map application system in function and characteristics; (2)propose the process for creating construction knowledge map; (3)propose important factors and analysis in knowledge map design. Furthermore, a construction classification structure is provided in the paper and a scenario is explained to describe the framework of building a construction knowledge map by studying literature reviews and consulting experts' symposia.

\subsection{Characteristics of Construction Environment}

Construction projects are usually unique. The characteristics, specifications, and execution plans of construction products are described in a large number of construction documents, such as contracts, specifications, meeting minutes, change orders, field reports, requests of information, drawings, schedules and cost estimates. In addition, there are not only many different kinds of positions as owner, designers in project team members, contractors and other stakeholder organization,, but also many kinds of file types such as structured data files, semi structured data files, unstructured text data files, unstructured graphic files and unstructured multimedia files. All of these contain a vast a mount of tacit knowledge. However, users often have difficulty obtaining and reusing such tacit knowledge.[2][3]

\subsection{The Benefit and Characteristic of Knowledge Map}

The main benefit and characteristic of knowledge map can summaried in the following [2]:

(1). Decision maker can know where the knowledge resource is.

(2). Help decision maker to confirm the scope of the industrial knowledge demand.

(3). Help decision maker to make the relative decisions about industry knowledge's assets.

(4). Help the superintendent to plan more a effective employee training program.

(5). Decreasing the employee's training program process to improve efficiency.

(6). When the strategies change, knowledge map can fulfill its function.

(7). Let each know their progress in the learning schedule.

(8). Compare the requirements and the achievements of industrial knowledge.

Besides, there are seven kinds of knowledge management maps listed the characteristic in Table 1. 


\section{Research Methodology}

This paper discusses how to apply knowledge maps in construction knowledge management. In current practice the Construction and Planning Agency in Taiwan established a committee group call "Construction Knowledge Management Map Project" to assist the construction industry in implementing knowledge management. The research consisted of conducting several expert symposia held by a committee group. The result of symposia is summarized in this paper.

\section{Construction Knowledge Management Map Project}

The Construction and Planning Agency in Taiwan have the "construction knowledge management map project", witch not only establish the committee group, expert symposia , and create a construction knowledge classification structure, but also set up the principles for construction knowledge map. All of the project execute are the important basis for implement knowledge management in construction industry.

\subsection{The committee group}

This research project includes 13 committee members at present time. The members were selected according fo their knowledge of a specialized domain, the combination of theory and practice in the construction industrial area and management group and so on.

In order to successfully establish the knowledge map, classification of construction, and the knowledge exchange standard, the committee must have a rich background in information development and combined fields. It must also have a suitable background in industry theory and also have multitudinous experiences in construction knowledge classifications, as well as the dynamic information platform plan and operation and so on, so that they can be of assistance in integration into the construction knowledge management knowledge base.

\subsection{Construction industrial classification structure}

Knowledge classifications structure classifies and codes the knowledge item in construction engineering in a systematic manner. Its main goals are to standardize the construction industry knowledge classification construction, and to integrate and store the information using codes. In this way, information can be made available to all and used more effectively.

Subsequently, this paper discusses the internal and foreign classification systems such as OCCS and UniClass. It also proposes the basis for the construction knowledge management system management code, as show in Table2 [2].

\subsection{Brief introduction of construction industrial knowledge map}

Research on related information about construction engineering is difficult to obtain. Moreover the overall information survey is unclear. Therefore, this research emphasizes the construction of a knowledge map.

The aim of this project is to establish a knowledge encyclopedia and knowledge map inquiry, reduce the scope inquiry and information survey, use a multiconstruction method, and confirms the relationship among information.

\subsection{The industrial classification construction principles}

This study forms the foundation of a knowledge map by using academic classification constructions as a reference: Basically, construction industrial classifications take the static state, fixed, the less degree of change as the basic consideration for the classification constructions. If there is not a complete basic construction, creating a brand-new classification construction will be a heavy cost, high error taken and investment reward rate behavior.

Except for the basic static classifications, the construction industry and the database users needs grow. If the knowledge base classifications application is limited, the database cannot be able to provide its outstanding function. Therefore, this study suggests using the combination of both static and the dynamic knowledge classification construction.

For example, a certain knowledge documents have been about excavated in the basement store up in some knowledge platform. This document has a high possibility of being related to material document concerning the owner, the construction company, the consultant firm, general constructor, the material supplier or the specialized contractor and so on. If only regarding the document as a structural engineering document, we will be retrieve it by unable to another path. It will cause enormous limitations in the application of this knowledge platform. Therefore, the dynamic construction industrial classification constructions will become a long-term execution strategy and goal for this research.

\subsection{Principles for construction knowledge map}

(1). Branches of the first classification construction layer should contain no more than ten categories; Branches of the second classified structure layer contain at least seven but no more than ten. 
(2). In the initial establishment of knowledge classification construction, a specialized group of experts discuss together first, and then,according to by the different position, choose the most valuable knowledge construction of each group.

(3). The knowledge documents of the training groups: First, take 30 articles as the training group from the branches of each classification construction. Each article shoule be a standard in the article length of less than 20 pages.

(4). Testing knowledge documents of the groups: Take 20 articles as the testing group from the branches of the each classification construction. Each a article should be a standard length of less than 20 pages.

(5). After passing the system test, the results still needed to be given as feedback to the experts for them compare and analyze.By doing so, the system could be updated to carry out the classification result.

(6). Knowledge maps establish axis by integrating three dimensions: project specialized technology, project application and life cycle.

Building a construction of the knowledge map materials classification could explain in different angles. First, focus on the industrial application project items, including construction, water resources, transportation and so on. We could conclude another knowledge technical classification dimension from the above classifications, like laws and regulations standard, construction management, structure engineering, geotechnical engineering, surveying engineering and environment engineering and so on. On its overlapping spot means it has the knowledge correlation of plan and the execution part. On knowledge correlation spot brings out the issue of grows plan, the design, the construction, the sustainable operation management, thus unfolds another construction management related dimensions. On the knowledge related crossover point, brings out the specialty tree shape knowledge structure and organizes a thorough knowledge network.

\section{Building scenarios analysis of knowledge map classification structure Stage1: The analysis of demand}

[Step 1] Investigate the knowledge classification structures that fit into the knowledge management organization's interior needs and implement it into the knowledge-managed organization. Then download the standard knowledge classification template from the Construction and Planning Agency, as show in Table 3 and Figure2.

\section{Stage2: The beginning of implementation}

[Step 2] Revise the classification structure until it belongs only to this organization by using the download classification template and the classifing situation in organization.

[Step 3] After revising the needed classification structure, choose different dynamic knowledge maps that fit into each department in organization.

[Step 4] Use the knowledge classification structure and knowledge map, established in the current stage, as the important foundation for knowledge implementation. Then add the knowledge encyclopedia provided by the Construction and Planning Agency as the knowledge resource from outside the organization, as show in Figure3.

\section{Stage3: Mature application}

[Step 5] In the mature application process, the main basis for judgment lies in tranforming, through knowledge classification and treatment, the company's existing knowledge documents into an existing knowledge management system. By doing so, is established the unique company's unique knowledge encyclopedia, as show in Figure4.

\section{Stage4. Internal sharing and creation stage}

[Step 6] After integrating the knowledge encyclopedia that was provided by Construction and Planning Agency and the company existing knowledge documents, share it among all members of the company simultaneously, or hand it over to the specific knowledge community to apply it and maintain it. Furthermore, create an updated knowledge document, and feed it back into the company interior system, as show in Figure5.

\section{Stage5.External dynamic renewals and feedback stage}

[Step 7] Of the exterior organizations like the Construction and Planning Agency and so on, update the established company interior knowledge encyclopedia, and feedback the information that is allowed for publication back to the organization or the trade union of the same business.

[Step 8] Feed the knowledge map that was revised for the company interior needs back to the Construction and Planning Agency as the brand-new inducts reference model inorder to enhance the knowledge map application benefit.

[Step 9] Feedback the knowledge classification structure which has been applied by company to the knowledge classification structure owned by the Construction and Planning Agency, and provide it as an important reference to the application of the companies in the same business, as show in Figure5.

\section{Conclusion}


Knowledge map application use information techniques such as document classification, information inquiry, and visualized information, etc. This article dose not focus on the theoretical application of each information technology, but rather establishes and explains knowledge map's application models through experts' discussion and situational analysis. This main reason for this is to expand and strengthen the knowledge map concepts and to extend its applications. However, the related research fields, such as document classification, information inquiry, visualized information and other information techniques should not be ignored. The way to bring out knowledge map's concept in construction industries is to establish a unified construction industries classification structure, construction thesaurus, as well as integrating and gathering all kinds of knowledge documents.

\section{Reference}

[1] Gordon, J. L., "Creating knowledge maps by exploiting dependent relationships." KnowledgeBased Systems, vol.13 (2000), pp.71-79.

[2] Caldas, C. H.,"Automated Classification of Construction Project Documents." Journal of Computing in Civil Engineering, October (2002), pp.234-243

[3] Woo, J.H.,'Dynamic Knowledge Map: reusing experts' tacit knowledge in the AEC industry." Automation in Construction, vol.13 (2004), pp.203207.

Table1 Current knowledge map characteristics

\begin{tabular}{|c|c|}
\hline Type & An expression introducing comparison \\
\hline 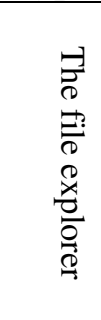 & $\begin{array}{l}\text { Instruction: This type uses a knowledge tree to show how knowledge is distributed. This type } \\
\text { could convenience the user by providing a fast and direct understanding of knowledge } \\
\text { classification and the distribution. This type of the existing knowledge map is often uses and } \\
\text { applied. } \\
\text { Advantages: Clear and fast direct understanding knowledge classification and distributed situation. } \\
\text { Shortcomings: This type is unable to use three-dimensional spaces to demonstrate the knowledge } \\
\text { classifications and distribution. It is also unable to express the correlation degree among } \\
\text { different knowledge types. }\end{array}$ \\
\hline 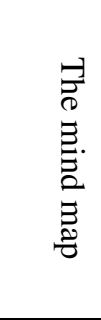 & $\begin{array}{l}\text { Instruction: Mind map expresses the knowledge distribution with the knowledge tree similar to the } \\
\text { human's thinking pattern. This type convenience the user by directly providing an understanding } \\
\text { of human's thinking patterns' distribution and the content. This is one of the existing knowledge } \\
\text { map display types. } \\
\text { Advantages: Clearly expresses the pattern of human thinking. It could reduce communication } \\
\text { gaps. } \\
\text { Shortcomings: It is not easy to express multi-dimension, using this type is also unable to express } \\
\text { the correlation degree among different knowledge types. }\end{array}$ \\
\hline 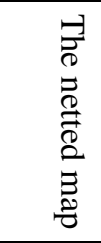 & $\begin{array}{l}\text { Instruction: The netted map type shows the knowledge distributions using the netted map. This } \\
\text { type is convenient because it allows the user to directly understand the main classifications of } \\
\text { knowledge and its correlation. It is generally applied to high correlation website content's linking. } \\
\text { Advantages: Provides a understanding of fast and direct knowledge correlation and distribution. } \\
\text { Shortcomings: It is not easy to express multi-dimensional knowledge using this system. It is also } \\
\text { unable to express the correlation degree among different knowledge types. }\end{array}$ \\
\hline 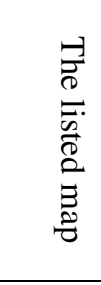 & $\begin{array}{l}\text { Instruction: This map expresses knowledge distribution by listing them. This type is convenient } \\
\text { because it allows the user to directly understand the knowledge classifications and the } \\
\text { distribution condition types. Fast construction is also the main superior of the listed map. It is } \\
\text { also one of the early knowledge map applications. } \\
\text { Advantages: The user is able to understand clearly knowledge classifications. } \\
\text { Shortcomings: It is unable to express the main scatter situations of knowledge. It is also unable to } \\
\text { show the correlation degree among different knowledge types. }\end{array}$ \\
\hline 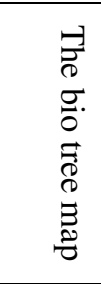 & $\begin{array}{l}\text { Instruction: This map shows the knowledge distribution by using a scattered map knowledge tree. } \\
\text { This type is mainly used to express the knowledge type classifications. Through the density and } \\
\text { the distance among spots, the map shows the knowledge map. } \\
\text { Advantages: The user is able to understand clearly knowledge classifications and distribution } \\
\text { situation. } \\
\text { Shortcomings: It is not easy to express multi-dimensional knowledge. It is also unable to express } \\
\text { the correlation degree among different knowledge types. }\end{array}$ \\
\hline
\end{tabular}




\begin{tabular}{|c|c|}
\hline Type & ducing comparison \\
\hline 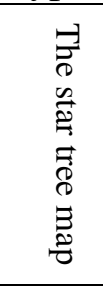 & $\begin{array}{l}\text { Instruction: This map shows the knowled } \\
\text { user have a clear understanding of the } \\
\text { classifications. It is one of the most often- } \\
\text { Advantages: This type can show clearly } \\
\text { facilitate the expression of the correlation } \\
\text { Shortcomings: It is unable or uneasy to ex }\end{array}$ \\
\hline 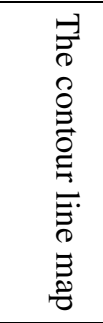 & $\begin{array}{l}\text { Instruction: This map shows the knowledge distribution by the contour line map shaped by } \\
\text { knowledge tree. This type is an application of three spatial expressions and the contour line } \\
\text { concept. It has the key advantage of visualizing the knowledge map. } \\
\text { Advantages: In three spatial expressions way, this map could improve the main barrier to } \\
\text { visualization. It ables the user to understand the knowledge classifications and distribution } \\
\text { situation in a non- abstract way. } \\
\text { Shortcomings: This type is unable to express the correlation degree among different knowledge } \\
\text { types. }\end{array}$ \\
\hline
\end{tabular}

Table2 Existing construction industrial classifications construction

\begin{tabular}{|l|l|}
\hline Items & Classifications introduction \\
\hline $\begin{array}{l}\text { The project } \\
\text { classification }\end{array}$ & $\begin{array}{l}\text { Owner (includes personally and government units), the construction company, the } \\
\text { consultant firm, general constructor, material supplier, specialized contractor, } \\
\text { specialized technician office }\end{array}$ \\
\hline $\begin{array}{l}\text { academic } \\
\text { classification }\end{array}$ & $\begin{array}{l}\text { Classify by the domestic and foreign academic specialized knowledge. The main } \\
\text { knowledge classification constructions are the architecture, the urban plan, the } \\
\text { environment engineering, the structural engineering, the geotechnical engineering, } \\
\text { the surveying engineering, the hydraulics engineering, transportation engineering, the } \\
\text { material engineering, construction management and so on. }\end{array}$ \\
\hline Others & OSSC, UniClass, construction patent and so on. \\
\hline
\end{tabular}

Table3 Scenarios analysis of knowledge map classification structure

\begin{tabular}{|l|c|c|c|}
\hline \multirow{2}{*}{$\begin{array}{l}\text { Knowledge Management } \\
\text { Application Stage }\end{array}$} & Knowledge Classification & Knowledge Type \\
\cline { 2 - 4 } & Classification Structure & Knowledge Map & Knowledge encyclopedia \\
\hline Demands analyzing stage & Step2 & Step3 & Step4 \\
\hline Start implementation stage & & & Step5 \\
\hline Mature applications stages & Step9 & Step8 & Step6 \\
\hline $\begin{array}{l}\text { Internal shares and the creation } \\
\text { stage }\end{array}$ & $\begin{array}{l}\text { External dynamic renewals and } \\
\text { feedback stage }\end{array}$ & &
\end{tabular}

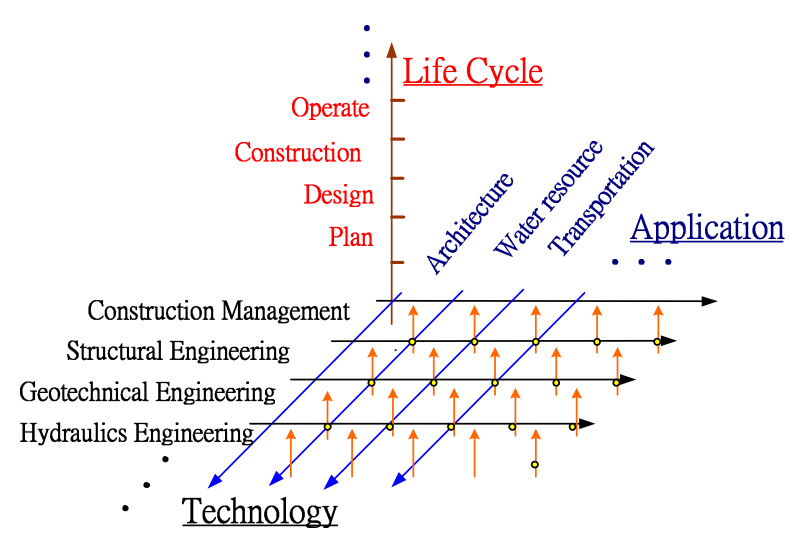

Figure1 Three dimensions of construction knowledge map matrix 


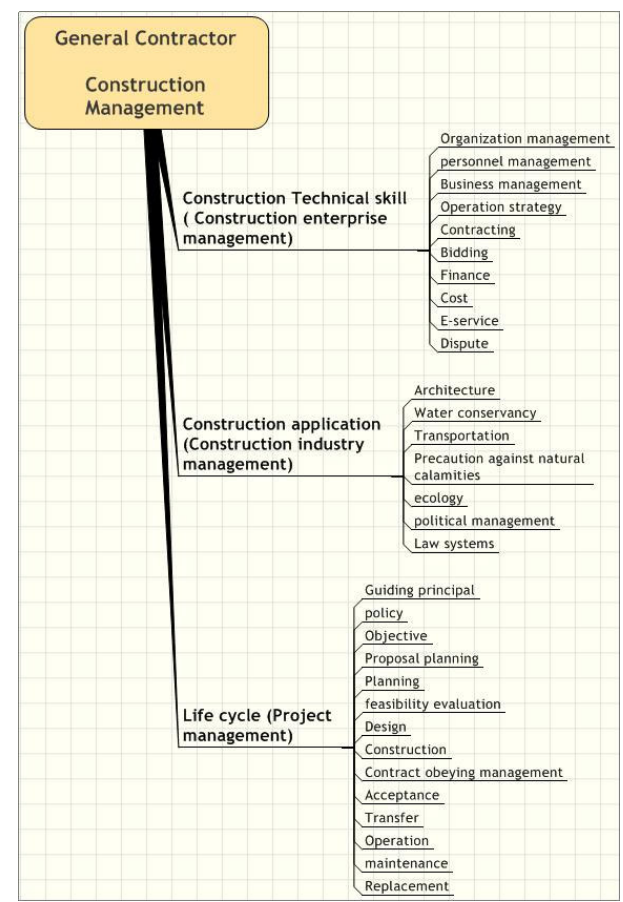

Figure2 Demands analyzing stage
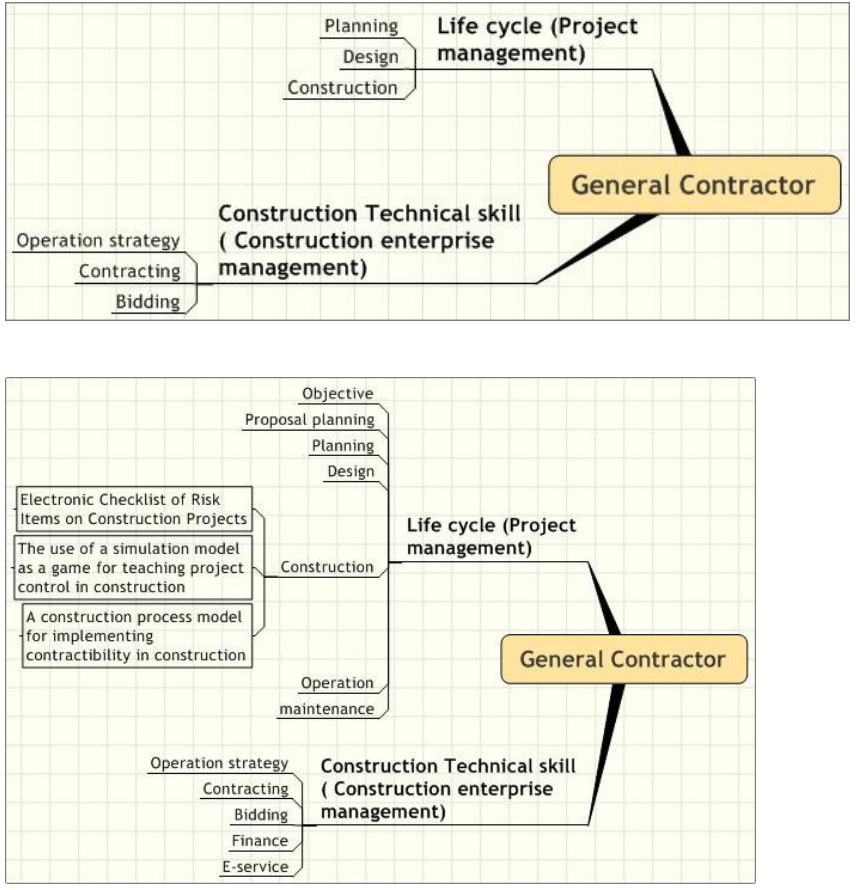

Figure3 Start implementation stage

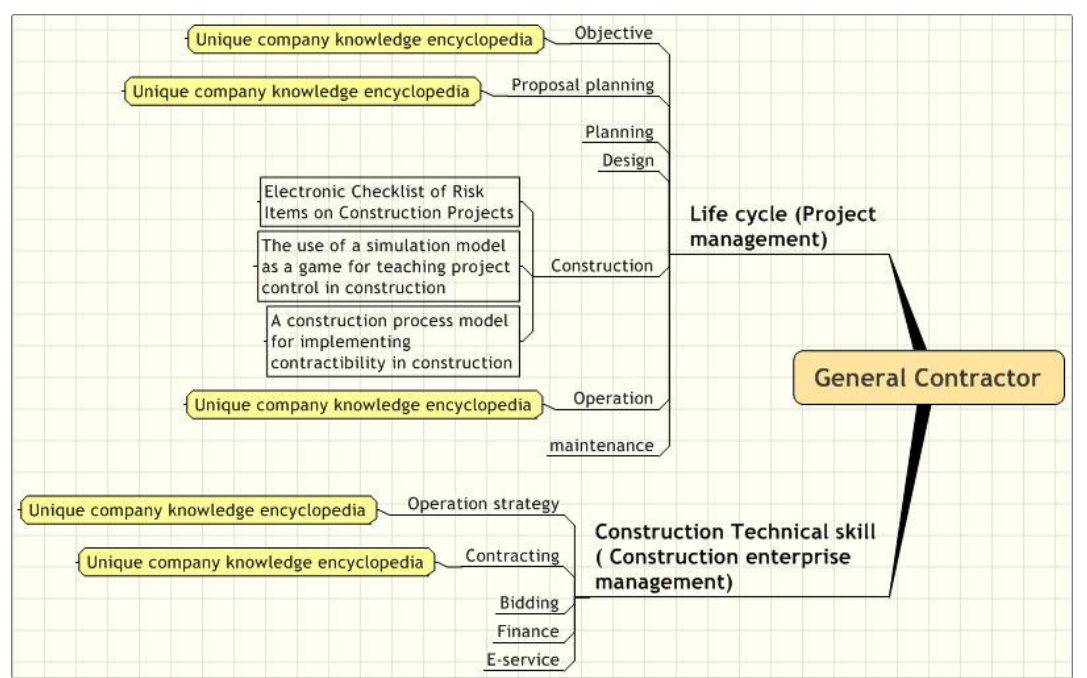

Figure4 Mature applications stages (unique company knowledge encyclopedia)

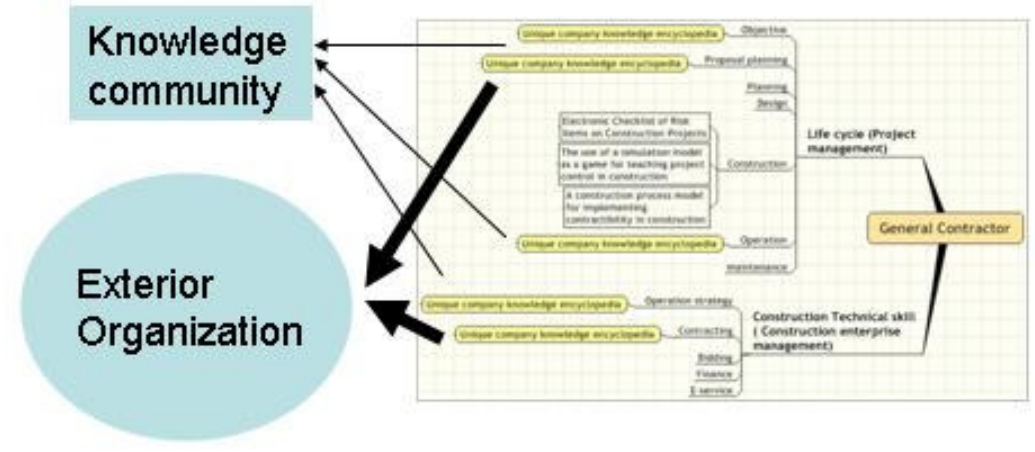

Figure5 Internal shares and the creation stage (knowledge community) External dynamic renewals and feedback stage (exterior organization) 